\title{
O IMPACTO DO PROGRAMA DE INCENTIVOS AO TREINAMENTO NAS EMPRESAS
}

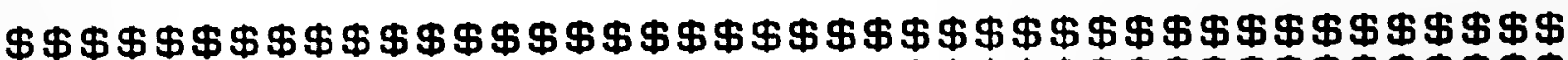

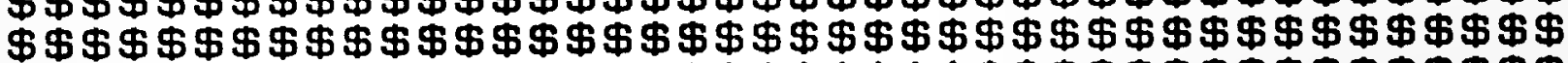

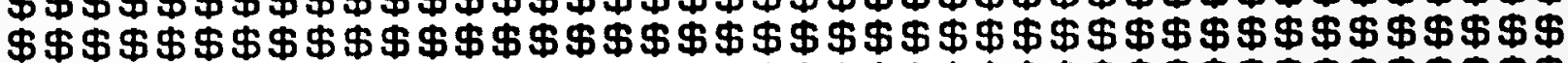

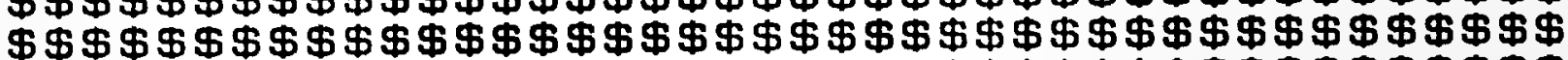

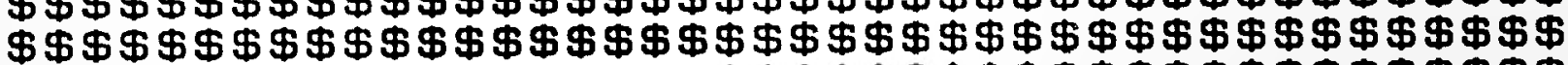

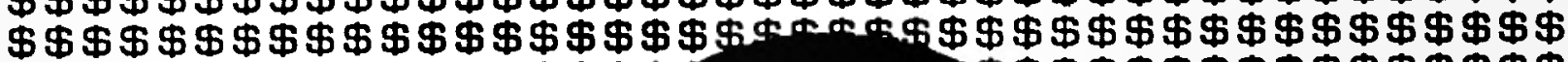

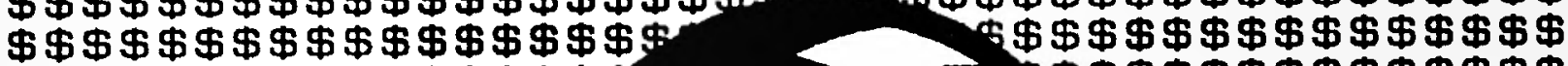

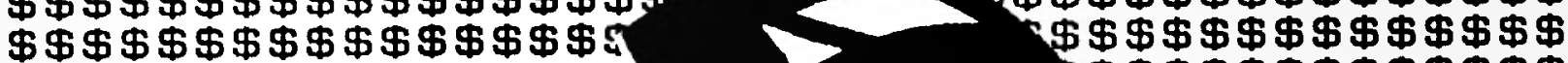

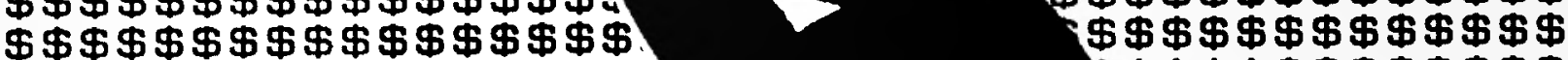

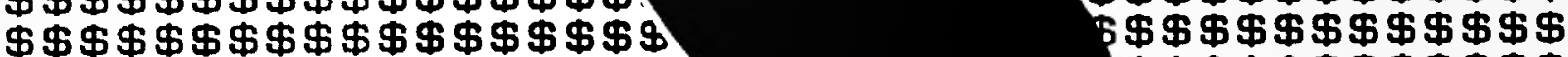

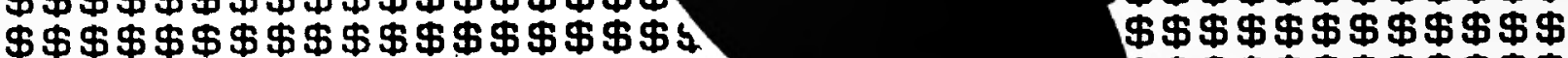

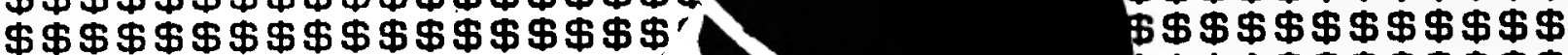

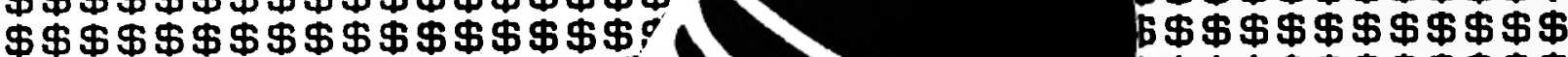

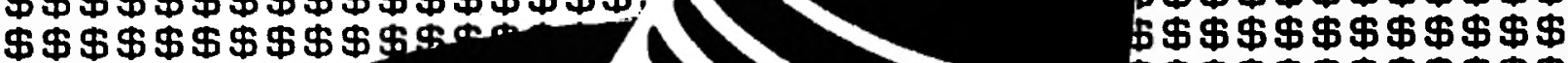

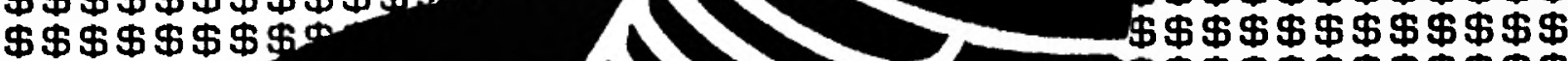

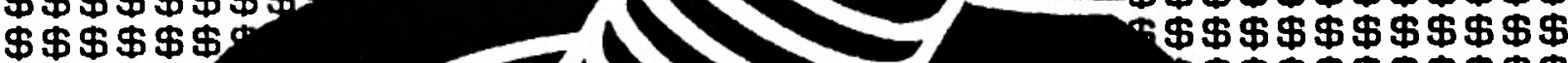
\$中象乐? 串事\$? 串事事 \$中象。

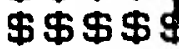

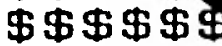

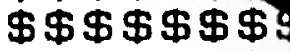

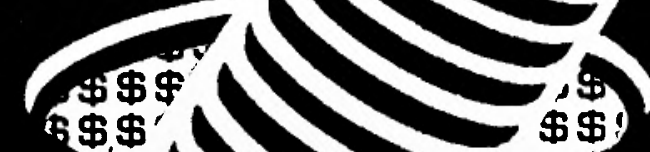
\$ $\$$

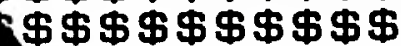

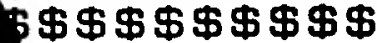
斗中\$\$中\$中\$\$

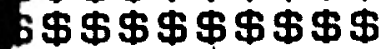

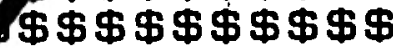

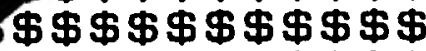

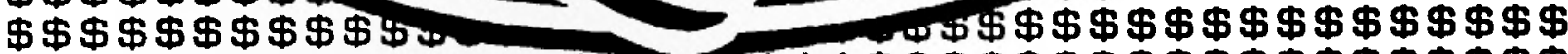

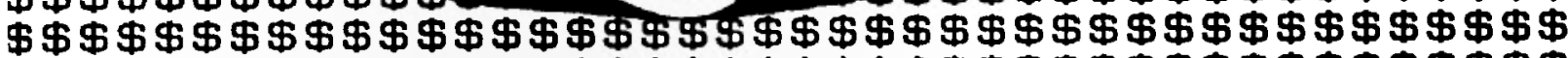

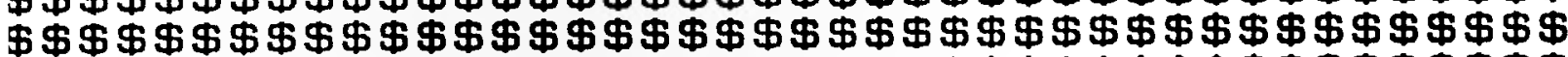

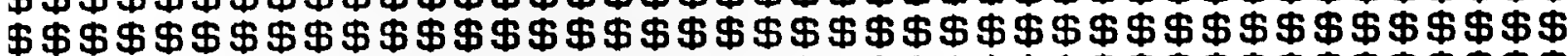

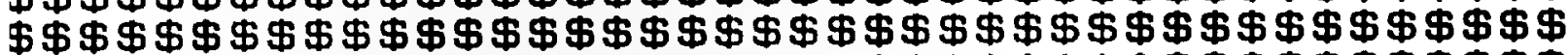

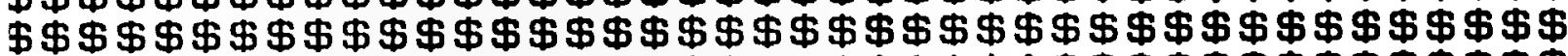

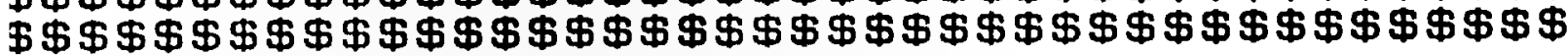

\section{SYLVIA ROESCH}

Professora do Programa de Pós-Graduação em Administração e do Departamento de Ciências Administrativas da UFRGS.

RESUMO: Este artigo arialia o programa de incentioos fiscais à fommaçāo profissional nas empresas introduzido no Brasil em 1976. Utiliza modelos da teoria econômica t' da teoria da organização. A pesquisa de campo foi conduzida em 1983 e abrangeu 44 empresas beneficiarias do programa. em diferentes setores da in- dústria no sul do Brasil. Em 1985, voltou-se a entrevistar oito dessas empresas. Os resultados sugerem que o programa aumentou o número de firmas que utilizam treinamento, embora não tenha aumentado o volume de treinamento naquelas empresas que já mantinham programas anteriormente. Ainda, o volume total de despesas de treinamento estimuladas foi menor do que os recursos investidos pelo governo.

PALAVRAS-CHAVE: Treinamento, incentivos fiscais, capital humano, avaliação de políticas, avaliação de impacto. 


\section{INTRODUÇÃO}

E m dezembro de 1975, o governo brasileiro criou um programa de incentivos fiscais para estimular as atividades de treinamento das empresas. O programa - instituído pela Lei $6.297 / 75$ - financia até um limite de $35 \%$ das suas despesas de treinamento. A dedução é feita diretamente no imposto de renda da empresa, mas é limitada a $10 \%$ do imposto pago. Os recursos que o programa oferece podem ser utilizados tanto para os cursos de treinamento - desenvolvidos pela empresa ou por entidades externas - como para despesas de administração das atividades de treinamento, ou ainda despesas de investimento que cobrem equipamentos e maquinária a serem utilizados nessas atividades, bem como a construção de centros de treinamento nas empresas. As empresas que desejam participar do programa devem submeter planos de treinamento ao Conselho Federal de Mão-deObra (CFMO) para aprovação prévia. Este texto descreve uma tentativa de avaliar o impacto desse programa no treinamento das empresas ${ }^{1}$.

De acordo com dados do Conselho Federal de Mão-de-Obra, o programa treinou um milhão de trabalhadores, ou $6 \%$ da força de trabalho em $1980^{2}$. A mesma fonte informa que o número de trabalhadores treinados com os recursos provenientes do programa equivale a um terço da força de trabalho das empresas que se beneficiariam dos incentivos ${ }^{3}$. Essas estimativas ignoram o fato de que muitos desses trabalhadores, talvez todos, teriam sido treinados pelas empresas na ausência do programa de incentivos.

Tendo como base os dados publicados pelo Ministério da Fazenda, observa-se que, no período de 1979 a 1981, o programa cobriu menos do que $1 \%$ da população alvo, ou seja, as 200.000 empresas que pagam imposto de renda no país. Do mesmo modo, o valor deduzido do imposto pelas empresas beneficiárias atingiu apenas $0,5 \%$ do imposto de renda pago por todas as empresas 4 . Considerando-se o período de 1976 a 1981, observa-se que a tendência é para uma estabilização no número das empresas beneficiárias a um nível de 2.000 empresas, aproximadamente ${ }^{5}$. Entre outras tendências, nota-se que o valor médio por empresa deduzido do imposto decresceu em $36 \%$ no período e que o treinamento realizado atinge apenas $40 \%$ do que foi inicialmente planejado pelas empresas. Detalhes na operação do programa, a alta taxa de inflação e a recessão econômica que caracterizam o final do período são fatores que possivelmente expliquem essas tendências.

Ao contrário das expectativas do governo de que o programa de incentivos ao treinamento seria um instrumento de desconcentração da renda regional ${ }^{6}$, observa-se que a distribuição das empresas beneficiárias de fato reproduz a estrutura de concentração do setor produtivo do país na região sudeste, já que $63 \%$ das empresas beneficiárias se localizam nessa região, $26 \%$ na região sul e os restantes $11 \%$ nas demais regiões. Quanto à distribuição setorial, observa-se que $51,5 \%$ das empresas beneficiárias pertencem ao setor industrial, enquanto que $29,9 \%$ se dedicam a atividades comerciais e $18,4 \%$, ao setor serviços. Essa distribuição, porém, modifica-se quando o critério de classificação é o montante do valor deduzido. Nesse caso, o setor serviços participa com $46,5 \%$,o setor industrial, com $45,0 \%$ e o setor comercial, com apenas $8,5 \%$. O setor financeiro explica a alta participação do setor serviços. As justificativas dadas pelo governo foram: os bancos são altamente intensivos em mão-de-obra e não há uma instituição de treinamento que atenda ao setor financeiro, ao con trário do setor industrial e do comercial, que são atendidos pelo SENAI e SENAC?.

No setor industrial, embora a maioria das empresas beneficiárias pertença ao setor metalmecânico, observa-se que a utilização dos incentivos na indústria manufatureira não se concentra de maneira desproporcional nesse subsetor. Quando se compara o valor deduzido do imposto com o número de trabalhadores empregados em cada subsetor da indústria, evidencia-se que a indústria farmacêutica e a do fumo são as mais intensivas no uso dos incentivos, seguida pela in-

1. Este artigo consiste basicamente num resumo do capítulo VIII da tese de doutoramento da autora, Public Policies Towards Industrial Training - The brazilian programme of fiscal incentives, apresentada à London School of Economics and Political Sciences, Londres, em 1987, 315 págs.

2. Ver CAMPINO, A.C.C. et alii. Recursos Humanos e Desempenho dos Programas de Formação de Mão-de-Obra. Brasília, Nobel, 1985.

3. Ver Conselho Federal de Mão-de-Obra, CAAD, 1981 (mimeo).

4. IMPOSTO de Renda Pessoa Jurídica. Ministério da Fazenda. Brasília, 1981-1983.

5. Idem, ibidem, 1978-1983, p.2.

6. PROCURAM-SE executivos $100 \%$ nacionais. In: Treinamento de Executivos, Brasília, no 25, jan/1976, pp.11-16.

7. Entrevista com L.G.Ferreira, que foi assessor do Ministério do Trabalho de 1974 a 1978 e participou ativamente da elaboração da Lei 6.297/75. 
dústria química e, em quarto lugar, pela indústria metal-mecânica.

A intensidade no uso dos incentivos na indústria manufatureira aumenta com o tamanho médio do estabelecimento, como foi demonstrado por uma análise de regressão múltipla. A interpretação desse resultado é que o programa tende a beneficiar primariamente as grancles empresas, como aliás acontece também com outros programas operados através de incentivos fiscais ${ }^{8}$. As razões devem-se tanto às facilidades de acesso que essas empresas têm a informaçôes sobre os programas oferecidos pelo governo como à própria margem de deduçào do imposto, que acaba tornando o incentivo pouco atrativo ou mesmo irrelevante para outras.

A maioria desses resultados está a sugerir que os incentivos fiscais não são o instrumento mais apropriado para operar o programa. Pode-se argumentar que enquanto a utilização seletiva dos incentivos seria um resultado que o governo poderia ter previsto, mudanças na economia parecem haver restringido a sua cobertura, já que o contexto mudou substancialmente do momento em que o programa foi concebido, em 1975, até sua popularização, anos mais tarde.

\section{OS OBJETIVOS DO PROGRAMA}

As expectativas do governo eram que esses incentivos, por um lado, ao aumentarem as oportunidades de treinamento oferecidas pelas empresas, estariam proporcionando oportunidades de educaçào permanente para os trabalhadores. Outro argumento era que o treinamento financiado pelo governo levaria a um aumento da produtividade do trabalhador 2 , com isso, aumentaria a produtividade das empresas, com resultados inclusive na produtividade da economia.

Esses resultados sĩo difíceis, senão impossíveis, de medir. Uma alternativa para medir o impacto do programa é utilizar um resultado intermediário, sem o qual nenhum desses resultados finais poderia ser alcançado'. Optou-se, entào, por medir se, de fato, os incentivos estimularam treinamento adicional pelas empresas.

A eficácia do programa vai depender antes de tudo da resposta dos empresários. A razão básica para que o governo tenha escolhido esse tipo de programa baseja-se, ao que parece, na idéia da racionalidade econômica do empresário, que supõe que as empresas produzam capital humano com um baixo custo. Os incentivos fiscais ao treinamento afetam o financiamento privado de treinamento. Nào importa quem estava financiando antes o treinamento, empresia ou trabalhador: os recursos são dirigidos a empresa, reduzindo, em princípio, um terço dos seus custos diretos em treinamento. A questão é, então, saber até onde esse recurso adicional vai provocar um volume adicional de treinamento pelas empresas e, naturalmente, que tipo de treinamento será estimulado pelos incentivos, já que a legislação não estabelece prioridade do ponto de vista do governo e que o único critério para a seleção das empresas beneficiárias é a consistência entre as sulas necessidades de treinamento e os planos de treinamento por ela propostos.

A teoria do capital humano (especialmente a de Becker $)^{10}$ argumenta que os empregadores investem em treinamento quando há uma alta probabilidade de obter retorno. Por essa razão, eles tendem a financiar treinamento específico, já que nesse caso é improvável que o treinado seja atraído por outras ofertas de emprego no mercado, ao contrário do que acontece com o treinamento geral que gera uma qualificação válida também para outras empresas. No caso do treinamento geral, segundo o modelo, quem paga o treinamento é o empregado, na forma de um salário inferior à sua produtividade, como no caso dos aprendizes.

O modelo de Becker é construído a partir de um conjunto de suposições sobre competência perfeita $\epsilon$, naturalmente, condições reais podem mudar as decisōes de investimento do empregador. Não parece haver, no entanto, no contexto brasileiro, características que venham a interferir negativamente nas decisões dos empregadores em investir em treinamento, já que não há controle dos sindicatos sobre a quantidade de treinamento a ser desenvolvido pelas empresas, nem efetivo controle dos sindicatos sobre o salário do trabalhador qualificado. Quanto à questão da rotatividade da mão-de-obra, observa-se que as taxas de turnover voluntário são baixas e, quanto à questão da rotatividade da mão-de-obra treinada, a evidencia disponível a respeito do treinamento do SENAI é que as empresas que mantêm a maior parte dos aprendizes são, ao mesmo tempo, as empresas preferidas pelos egressos, já que lhes pagam melhores salários e lhes oferecem melhores condições de trabalho ${ }^{11}$.

8. PENÁLILER, M. et alii. Política Industrial e Exportação de' Manufuturudos do Brasil. Rio de Janeiro, Fundação Getúlio V'argas, 1983.

9. MORRIS, L.L. \& FITZ-GIBBON, C.T. How to Deal with Goals and Objectives. Londres, Sage, 1978.

10.BECKER, G. Human Capital - A theoretical and empirical antysis, with special reference to education. Chicago, University of Chicago, 1975.

11.L.EJTF, E.M. \& CAILLODS, F. Educaçāo, Treinamento e Empre'go na Pequena Empresa. São Paulo, Serviço Vacional de Aprendizagem Industrial/International Institute for Educational Planning, 1985. 
Segundo esse enfoque, não há razão para se esperar um aumento no volume de treinamento como resultado dos incentivos. O modelo pode predizer, ao contrário, que os empregadores vão usar os recursos providos pelo programa para pagar treinamento específico, o qual eles teriam de financiar de qualquer maneira. Ainda, o modelo considera que os empregadores oferecem treinamento geral na condição de que não tenham de pagar por ele. Nesse caso, teríamos de perguntar se, quando o governo financia um terço do custo do treinamento, ele está a oferecer um estímulo suficiente para fazer o empregador prover esse tipo de treinamento (ou oportunidades de educação permanente), como foi definido pelos que conceberam o programa.

Outros enfoques, no entanto, apresentam razões para que os empregadores aumentem seu volume de treinamento como resultado dos incentivos. $\mathrm{O}$ enfoque de ajustamentos de mão-deobra $^{12}$ chama a atenção sobre as várias alternativas à disposição dos empregadores para combater problemas de escassez de mão-de-obra. $\mathrm{O}$ treinamento é considerado como uma alternativa temporária e facilmente reversível, assim como é também o caso de políticas de seleção ou de subcontratação de mão-de-obra. Pode-se argumentar que a existência do programa de incentivos fiscais torna o treinamento uma alternativa mais atrativa do que outros instrumentos.

O enfoque do mercado interno de trabalho ${ }^{13}$ enfatiza a necessidade do treinamento em serviço, já que a existência de mercado interno de trabalho na empresa dificulta a contratação de trabalhadores já qualificados. $O$ enfoque também ressalta as vantagens do treinamento em serviço, assim como chama a atenção para o inter-relacionamento entre treinamento e outras políticas de mão-deobra. $\mathrm{O}$ fato de que o treinamento pode ser usado como um instrumento de seleção, por exemplo, representa uma razão adicional para que os empregadores aumentem seus investimentos em treinamento, como resultado do programa.

O enfoque da administração destaca as vantagens para a empresa em prover treinamento sistemático, o qual decorre da criação de estruturas permanentes de treinamento ${ }^{14}$. Além do desenvolvimento de qualificações, o enfoque dá ênfase ao desenvolvimento de atitudes de lealdade à empresa como resultado do treinamento ${ }^{15}$. Nesse sentido, esse enfoque também reforça a idéia de que a existência do programa de incentivos induziria a um aumento em atividades de treinamento na empresa.

Na justificativa do programa de incentivos, está implícita a idéia do empregador como um in- vestidor a longo prazo em capital humano. Essa idéia, entretanto, representa tanto realidade como um ideal a ser atingido: realidade, para uma minoria de grandes empresas multinacionais e consórcios e, talvez, algumas empresas nacionais; ideal, para a grande maioria de pequenas empresas do país. Enquanto parece haver uma expectativa do governo de que aquelas empresas que tradicionalmente desenvolvem atividades de treinamento venham a intensificar as suas atividades e, em certo sentido, treinar para o mercado, outro objetivo do governo é ensinar ao último grupo de empregadores as vantagens de financiar ou prover treinamento sistemático. Por essa razão, o programa financia a construção, manutenção e administração de estruturas internas de treinamento.

\section{MÉTODO}

A pesquisa se baseia numa amostra de empresas que utilizaram os incentivos ao treinamento no Rio Grande do Sul, considerando o período de 1976 a 1982. Esse Estado coloca-se em segundo lugar, em termos de empresas beneficiárias do incentivo e em quarto lugar, em termos do valor deduzido no imposto. A seleção da amostra observou os seguintes passos:

a) a partir de uma lista, fornecida pelo CFMO, das 361 empresas que utilizaram o incentivo pelo menos uma vez no período de 1976 a 1982, excluiram-se aquelas empresas que desistiram do programa após havê-lo utilizado por apenas um ou dois anos, na maioria dos casos;

b) dentre as 254 empresas restantes, separaram-se as 129 empresas pertencentes ao setor industrial; e por fim

c) calculou-se uma amostra estratificada de acordo com o tamanho das empresas; esta atingiu um total de 44 empresas.

Embora a amostra possa ser considerada pe-

12.THOMAS, B. \& DEATON, D. Labour Shortage and Economic Analysis. Oxford, Warwick Studies of Industrial Relations, Basil Blackwell, 1977.

13.DOERINGER, P.B. \& PIORE, M. Internal Labore Markets and Manpower Analysis. Lexington, Mass., D.C. Heath, 1971.

14.Ver, por exemplo, HAMBLIN, A.C. Evaluation and Control of Training. Londres, McGraw-Hill, 1974; e KENNEY, J. et alii. Manpower Training and Development. Londres, Institute of Personnel Management, 1981.

15.PETERS, T.J. \& WATERMAN Jr., R.H. In Search of Excellence. New York, Harper \& Row, 1982. 
quena, ela representa $20 \%$ das empresas do Estado com mais de 500 trabalhadores. As empresas da amostra empregam 51.000 trabalhadores, o que representa $10 \%$ dos trabalhadores empregados na indústria gaúcha. A amostra é predominantemente composta por empresas nacionais privadas, compreendendo apenas quatro empresas multinacionais e quatro estatais.

O levantamento foi realizado em 1983, através de questionário dirigido aos responsáveis pelo treinamento das empresas. Este consistiu de 20 questões que enfatizaram dados físico-financeiros sobre o programa de incentivos e a política de treinamento das empresas. Para a análise, todos os valores em cruzeiros foram corrigidos para o ano de 1982, utilizando-se o índice geral de preços da Fundação Getúlio Vargas.

\section{AVALIAÇÃO DO IMPACTO}

Talvez o melhor meio de avaliar os resultados de programas públicos seja comparar informação sobre participantes e não participantes, antes $\mathrm{e}$ depois da iniciativa ${ }^{16}$. Esse procedimento implicaria em pesquisar empresas beneficiárias e não beneficiárias do incentivo e levantar informações sobre a situação antes e depois da utilização do incentivo. Isso provou ser impossível de se realizar. Praticamente, nenhuma das empresas da amostra mantinha informações sobre os seus programas de treinamento no período anterior à utilização dos incentivos, já que a empresa não necessita contabilizar despesas de treinamento separadamente das despesas de mão-de-obra. Considerando que mesmo o grupo de empresas beneficiárias - que afinal compreende as maiores empresas que oferecem treinamento aos seus empregados - não possuía informações sobre treinamento antes da utilização dos incentivos, seria muito improvável esperar que empresas não beneficiárias dispusessem dessas informações. Isso tornou impossivel utilizá-las como grupo de controle. Pela mesma razão, tornou-se impossivel conduzir uma análise antes e depois restrita ao grupo de empresas beneficiárias. Diante dessas dificuldades, optou-se por uma análise por coortes (cohort analysis), de acordo com o ano em que a empresa ingressou no sistema de incentivos, utilizando as despesas de treinamento da empresa como variável básica. Essa análise foi complementada por uma avaliação, dos responsáveis pelo treinamento das empresas, das variações nas despesas de treinamento e no volume de treinamento financiado pela empresa antes e depois do incentivo. Os procedimentos e resultados dessas análises são resumidos a seguir.

\section{Análise por coortes}

$\mathrm{Na}$ busca de alternativas para avaliar o impacto desse programa, pensou-se em comparar mudanças nas despesas de treinamento das empresas entre o primeiro e o último ano em que estavam utilizando os incentivos. Essa idéia não foi posta em prática por duas razões, que estão ligadas ao ciclo econômico, já que o período em análise era especialmente instável. Primeiro, porque tal comparação entre despesas de treinamento ao longo do tempo não revelaria as variações no meio do período; segundo, esse procedimento envolveria a comparação de diferentes anos para empresas diferentes, já que seu ano inicial no uso dos incentivos varia.

Uma alternativa melhor pareceu-nos ser a de comparar as variações nas despesas de treinamento das empresas entre o primeiro e o segundo ano em que utilizaram os incentivos. A suposição aqui foi que essa comparação seria a que melhor refletiria o efeito dos incentivos, enquanto que nos anos seguintes, mesmo que a empresa continuasse utilizando os incentivos, esse efeito teria sido absorvido nas despesas de treinamento da empresa; e a diferença entre, por exemplo, o segundo e o terceiro ano, o terceiro e o quarto, e assim por diante, seria devida a outros efeitos.

$O$ procedimento utilizado na análise foi o de distribuir as empresas beneficiárias por coortes, de acordo com o ano em que iniciaram a utilização dos incentivos. A tabela 1 apresenta as despesas totais de treinamento para as empresas segundo essa classificação. $O$ passo seguinte foi, então, calcular taxas de mudanças nas despesas de treinamento entre o primeiro e o segundo anos, como também para cada par de anos subseqüentes, para cada empresa, como se pode observar na tabela 2 .

A partir desse procedimento, foi possível isolar dois efeitos diferentes: o efeito dos incentivos e o efeito do ciclo econômico nas despesas de treinamento das empresas. Nossa medida do efeito dos incentivos é definida pelos valores sublinhados no lado esquerdo da tabela e ao pé de cada coorte. Entre estes, a melhor medida do impacto dos incentivos é a taxa de mudança entre 1977 e 1976, já que se pode supor que o treinamento financiado em 1976 já estava planejado pela empresa quando o programa de incentivos fiscais começou a operar. A segunda melhor medida é a que envolve a comparação dos anos 1978 e 1977, mas restrita às

16.ROSSI, P.; FREEMAN, H.E.; WRIGHT, S.R. Evaluation: a systematic approach. Londres, Sage, 1979. 
firmas que iniciaram o programa em 1977; a terceira melhor medida refere-se à taxa de mudança entre os anos 1979 e 1978, mas restrita às firmas que iniciaram o programa em 1978, e assim por diante.

O efeito do ciclo econômico na despesa de treinamento das empresas pode ser observado nos demais valores. Tendo definido esses dois efeitos, o passo seguinte foi então conduzir uma análise por coortes e comparar ambos os efeitos. A fim de possibilitar essa análise, os valores na tabela 2 foram distribuídos em 21 células, com a finalidade de:

a) isolar o efeito dos incentivos em relação ao efeito do ciclo econômico; $\mathrm{e}$

b) permitir uma comparação dentro de cada coorte.

A partir dessas taxas de mudança, quatro medidas foram calculadas para cada subgrupo: a média, a mediana, a média ponderada e a percentagem de firmas que aumentaram suas despesas de treinamento (ver tabelas, de 3 a 6 ).

Observa-se que as quatro medidas calculadas oferecem evidência em favor de um impacto positivo dos incentivos, com exceção dos períodos $1978 / 77$ e 1981/80. A tabela 7 resume esses resultados. Ainda, ao repetir essa análise para uma outra medida - despesas de treinamento por empregado - encontrou-se um resultado muito similar.

Como resultado do procedimento acima, sabemos que os incentivos obtiveram um impacto positivo. Mas o resultado não nos permite saber o tipo ou a quantidade de empresas nas quais - como resultado do incentivo - houve um aumento de despesas de treinamento. $O$ passo seguinte dessa investigação foi, então, o de procurar complementar o resultado acima a partir da avaliação feita pelos responsáveis pelo treinamento entrevistados na pesquisa.

\section{A avaliação dos responsáveis pelo treina- mento}

Essa avaliação foi baseada em duas variáveis. A primeira diz respeito às variações nas despesas de treinamento da empresa, durante o período em que estavam utilizando os incentivos, onde as despesas de treinamento são classificadas como aumentando, estáveis ou diminuindo. A segunda diz respeito a mudanças no volume de treinamento oferecido pela empresa nos períodos anterior e posterior à utilização dos incentivos.

A variação nas despesas de treinamento da empresa foi comparada com outras três variáveis. A primeira refere-se ao que chamamos de história de treinamento da empresa. Nesse caso, a amostra foi dividida em dois grupos: um de empresas que tradicionalmente desenvolviam programas de treinamento; o outro, de empresas que começaram a desenvolver treinamento a partir do momento em que ingressaram no sistema de incentivos (ver tabela 8). Embora o chi-quadrado calculado de 3,27 não seja significante a um nível de $5 \%$, o resultado indica que as empresas iniciantes no treinamento estão a receber um maior impacto dos incentivos, já que apresentam uma maior proporção de empresas com variação positiva em suas despesas de treinamento.

A época em que as empresas iniciaram a utilizar os incentivos foi a segunda variável que se comparou com a variação nas despesas de treinamento. Observa-se, na tabela 9, que empresas que ingressaram mais tarde no programa de incentivos apresentam uma percentagem significantemente maior (o chi-quadrado calculado de 10,84 é significante a um nível tão baixo quanto $1 \%$ ) de empresas que declararam aumento em suas despesas de treinamento no período.

A terceira variável definida foi o grau de sofisticação da política de treinamento da empresa. Esta foi construída a partir de uma escala bastante rudimentar composta por quatro questões que dizem respeito à existência de política explícita de treinamento na empresa, à existência de política de treinamento expressa em documento escrito, à existência de avaliação de treinamento e, por fim, ao nível de avaliação de treinamento existente na empresa. Os resultados na tabela 10 mostram que existe alguma associação direta (o chi-quadrado calculado de 5,81 é significante apenas a um nível de $10 \%$ ) entre as duas variáveis. Ou seja, quanto maior o nível de sofisticação da política de treinamento da empresa, maior a probabilidade de que as empresas aumentem suas despesas de treinamento.

É ainda interessante observar que, quando o grau de sofisticação da política de treinamento da empresa é comparado com a sua história de treinamento, como na tabela 11, não se encontram diferenças significantes entre empresas iniciantes e estabelecidas em treinamento (chi-quadrado de 0,49 ). Esse resultado parece indicar que o programa de incentivos teve um impacto bastante positivo em desenvolver estruturas de treinamento nas empresas iniciantes.

Uma outra maneira de avaliar o impacto do programa foi a de solicitar aos responsáveis pelo treinamento das empresas que avaliassem se o volume de treinamento financiado pela empresa foi considerado "abaixo", "igual" ou "acima" das suas necessidades imediatas de treinamento, nos 
períodos antes e depois da utilização dos incentivos. A alternativa "acima das necessidades" não foi escolhida em nenhuma das vezes; ela foi, de fato, considerada absurda pelos respondentes.

A classificação resultante, de acordo com a tabela 12 , permite observar que a maioria das empresas não apresentou mudanças na sua política de treinamento ao utilizar os incentivos. $\mathrm{Na}$ verdade, 19 empresas já estavam treinando de acordo com suas necessidades imediatas e simplesmente mantiveram a mesma política ao utilizar os incentivos; 11 empresas declararam estar treinando abaixo de suas necessidades imediatas antes e depois da utilização dos incentivos; e das 12 empresas que mudaram de posição, uma declarou decréscimos no seu volume de treinamento (alegando crise financeira) e as outras 11 declararam aumentos no volume de treinamento.

Para o grupo das 19 empresas que declararam ter sempre investido para alcançar as suas necessidades imediatas de treinamento, os respondentes declararam explicitamente que a presença dos incentivos não exerceu nenhuma mudança em sua política de treinamento. As indicações são, portanto, que para essas empresas os incentivos estariam simplesmente custeando programas de treinamento que teriam sido desenvolvidos de qualquer modo.

No que se refere ao grupo composto por 11 empresas que declararam estar treinando abaixo das suas necessidades imediatas, tanto antes como depois da utilização dos incentivos, a razão principal foi a redução em custos administrativos. E interessante observar, porém, que, em quatro dessas empresas, o volume de treinamento atual estava aquém das necessidades da empresa porque o departamento de treinamento era recente e ainda não havia coberto todas as áreas da empresa, mas a tendência apontava para uma expansão das atividades de treinamento da empresa, por uma possível influência dos incentivos.

Finalmente, ao se examinar o grupo de $11 \mathrm{em}$ presas que declararam uma mudança para melhor em sua política de treinamento, evidenciouse que o programa contribuiu para o desenvolvimento de estruturas de treinamento e uma mudança na atitude dos empregadores em relação a essa atividade.

\section{Quantificando o impacto do programa}

O que se propõe a seguir é uma tentativa de quantificar o impacto do programa. Em termos muito gerais, vamos analisar a relação de custo/benefício do programa do ponto de vista do governo. Os custos se referem ao valor deduzido do imposto; os benefícios são representados pelo total de despesas em treinamento das empresas.

A partir da análise das respostas dos entrevistados, foi possível identificar aquelas empresas que declararam que o programa teve um impacto positivo em sua política de treinamento. Tendo examinado cuidadosamente cada caso, podemos reformular a classificação constante na tabela $\mathbf{1 2}$ em dois grupos apenas: aquele composto por empresas onde o programa produziu um impacto e outro onde o programa não produziu impacto. $O$ primeiro grupo inclui as 11 empresas que declararam uma mudança positiva em suas políticas de treinamento, acrescido de mais quatro empresas que, apesar de declararem estar treinando abaixo de suas necessidades nos dois momentos, estavam, no entanto, apresentando aumentos em suas despesas de treinamento. $O$ outro grupo das empresas onde o programa não produziu impacto - compreende as 29 empresas restantes.

Ainda, dada a falta de informações sobre as despesas de treinamento para quatro empresas (três pertencentes ao grupo com impacto e uma pertencendo ao grupo sem impacto), a amostra ficou reduzida a 40 firmas, onde 12 estão classificadas no grupo com impacto e 28 no grupo sem impacto. Tendo definido esses dois grupos, o próximo passo foi calcular para cada um deles a média ponderada da taxa de mudança nas despesas de treinamento para cada coorte.

A tabela 13 mostra as taxas calculadas. Observa-se que empresas com impacto não estão representadas em dois dos coortes (1979/78 e 1981/80). As comparações, então, limitam-se aos quatro coortes que compreendem ambos os grupos e às 26 empresas que estão representadas nesses quatro coortes (veja tabela 14). Outra observação é que todas as taxas sublinhadas - que representam o impacto dos incentivos -, exceto uma, são maiores no grupo com impacto do que no correspondente grupo sem impacto.

Uma maneira de obter uma medida global para cada grupo é calcular uma média das taxas que representam o impacto dos incentivos em ambos os grupos, ponderada pelo número de empresas em cada coorte. Ao proceder desse modo, obtivemos uma taxa de $66 \%$ para o grupo com impacto e de $28 \%$ para o grupo sem impacto. Esse resultado implica que o aumento nas despesas de treinamento do grupo com impacto foi aproximadamente duas vezes maior do que no grupo sem impacto.

A partir desse resultado, é possível prosseguir numa avaliação das cifras sobre despesas de treinamento para esses quatro coortes. Se se aceita que o grupo com impacto dobrou suas despesas 
de treinamento, a implicação é que essas empresas teriam gasto a metade dos valores observados na ausência dos incentivos, enquanto que o grupo de empresas sem impacto teria gasto o mesmo valor que foi observado. Portanto, a soma de ambos os valores na linha quatro da tabela 14 representa as despesas de treinamento que seriam feitas na ausência do programa. A partir daí, calculamos uma taxa aproximada do impacto do programa para cada coorte (ver linha 5 da tabela 14). A média aritmética dessas taxas é de $18 \%$, enquanto que a média ponderada (relativa ao número de firmas em cada coorte do grupo em impacto) é de $20 \%$. Esse resultado nos permite afirmar que o programa produziu um impacto da ordem de 18 a $20 \%$ nas despesas de treinamento das empresas entrevistadas.

A próxima questão é saber até que ponto esse benefício foi válido em relação à receita que o governo deixou de arrecadar. Um modo de analisar esse resultado é considerar duas alternativas do ponto de vista do governo: oferecer treinamento diretamente ou financiar treinamento através das empresas, na suposição de que ambos são de mesma qualidade. Então, voltando à tabela 14, pode-se observar que para essas 12 empresas com impacto, para os quatro coortes, as despesas de treinamento estimuladas pelo incentivo atingiram Cr\$ 41,3 milhões (em valores constantes de 1982). Essa soma foi gerada por uma correspondente dedução do imposto da ordem de $\mathrm{Cr} \$ 22,6$ milhões. A conclusão é, então, que cada cruzeiro investido pelo governo gerou 1.8 cruzeiros em despesas de treinamento pelas empresas.

Até agora foi demonstrado que o programa produziu impacto numa fração das empresas beneficiárias e que a quantidade de despesas de treinamento geradas correspondeu a quase o dobro do valor investido pelo governo. Entretanto, também ficou evidenciado que o programa não produziu impacto na maioria das empresas beneficiárias. É preciso, então, saber se o treinamento extra financiado pelo grupo com impacto valeu a pena em relação à receita não arrecadada correspondente a todas as empresas em todos os coortes. A suposição é que empresas no grupo com impacto tiveram uma despesa de treinamento duas vezes maior do que teriam na ausência do incentivo, para cada ano em que utilizaram o programa, enquanto que as empresas do grupo sem impacto não tiveram nenhuma mudança em suas despesas de treinamento em nenhum dos anos.

A soma das despesas de treinamento das empresas no grupo com impacto atingiu $794.778 \mathrm{mi}-$ lhões de cruzeiros. A metade desse valor, ou 297.391 milhões de cruzeiros, representa a quantia estimulada pelo programa. A soma do valor deduzido para todas as empresas para o total do período atingiu 526.847 milhões de cruzeiros. A relação dessas duas cifras permite-nos concluir que, considerando todas as empresas de amostra para o período 1976-1982, cada cruzeiro investido pelo governo gerou apenas 0,75 cruzeiros em despesas de treinamento pelas empresas beneficiárias.

A tabela 15 mostra essa proporção para cada ano do período. Ela permite observar que o programa teve inicialmente um impacto forte, ou seja, os 6.7 milhões de cruzeiros investidos em 1976 geraram 13.9 milhões de cruzeiros em despesas de treinamento pelas empresas. Então, ao financiar essas empresas, o governo duplicou a quantidade de treinamento. Se o governo tivesse oferecido treinamento diretamente, a despesa de treinamento seria igual ao valor deduzido ou $6.7 \mathrm{mi}$ lhões de cruzeiros.

Esse impacto positivo inicial, entretanto, não se repetiu nos anos seguintes. Ao contrário, as taxas apresentadas na linha quatro da tabela 15 sugerem dúvidas sobre a validade do programa, já que o volume de treinamento estimulado foi menor do que o recurso investido. A conclusão é, pois, que os recursos públicos teriam sido investidos de uma maneira mais lucrativa se o governo tivesse oferecido treinamento diretamente, ao invés de utilizar as empresas; ao menos, é claro, que o governo considere que o treinamento desenvolvido pelas empresas seja de melhor qualidade do que aquele que o governo pode desenvolver diretamente.

\section{DISCUSSÃO DOS RESULTADOS}

Os motivos que orientam as práticas de treinamento dos empregadores são ainda um tanto desconhecidos no Brasil, já que a literatura na área de Administração de Pessoal é basicamente de origem estrangeira. Entretanto, parece ser comumente aceito entre os profissionais de treinamento que não existem atitudes favoráveis ao treinamento na maioria das empresas. A maioria dos empregadores encara o treinamento como um custo e não como um investimento. Além disso, os responsáveis pelo treinamento nas empresas normalmente não tornam explícitos os benefícios do treinamento para o empregador. Outra explicação é que os empregadores vêem treinamento como luxo, desperdício ou um fringe benefit para o empregado ${ }^{17}$. Essa questão não foi investigada com detalhe neste estudo. Entretanto, alguns

17.PROCURAM-SE executivos $100 \%$ nacionais. Op. cit., p.2. 
dos resultados encontrados podem ser relacionados com os modelos brevemente apresentados na seção "Os Objetivos do Programa". Alguma evidência foi encontrada de que melhoria no desempenho do trabalhador e desenvolvimento de novas habilidades são os principais benefícios do treinamento percebidos pelos respondentes.

Como foi demonstrado, o programa de incentivos produziu, por um lado, um impacto positivo ao estimular empresas a iniciarem atividades de treinamento. Estas representam 30\% das empresas que se beneficiaram dos incentivos. Por outro lado, no entanto, foi constatado que o programa não produziu nenhum impacto na maioria das empresas, já que os recursos investidos não provocaram despesas adicionais com treinamento pelas empresas, além daquelas que elas estariam dispostas a incorrer na ausência do programa.

Esse resultado aparenta ser consistente com as predições do modelo de Becker. Considerando que os empregadores podem utilizar o recurso para financiar qualquer tipo de treinamento, não é surpreendente descobrir que o principal resultado do programa tenha sido o de financiar treinamento que seria desenvolvido de qualquer modo.

É difícil conduzir planejamento de mão-deobra no Brasil. Primeiro, em virtude das constantes mudanças na economia e da alta inflação. Em conseqüência, a prática corrente é recorrer a ajustamentos de mão-de-obra em lugar de treinamento's. Outra razão, de acordo com o enfoque de ajustamentos de mão-de-obra, é que o controle dos ajustamentos não ocorre dentro de um só departamento da empresa. Esse fato é agravado pela baixa importância dada ao departamento de treinamento na estrutura de decisão da empresa. Ambos os fatos são bem ilustrados no caso de algumas dessas empresas ${ }^{19}$ que, brevemente, descrevemos a seguir.

No caso da companhia que denominamos "Multinacional de Baixo Treinamento S.A.", o departamento de treinamento esteve desativado entre os anos 1979 e 1983, e, na época do primeiro levantamento, o responsável pelo setor não foi capaz de fornecer informação consistente sobre a política de treinamento da empresa, nem sequer encontrar cópias dos programas de treinamento anteriormente submetidos ao CFMO.

No caso de outra empresa, "Nacional de Baixo Treinamento S.A.", como resultado do programa de incentivos, um novo departamento de recursos humanos foi nela criado, em 1981, cobrindo as áreas de treinamento, recrutamento, relações industriais e psicologia. Dada a recessão, entretanto, o departamento de recursos humanos foi extinto em 1983.
Na empresa denominada de "Centro de Treinamento Ltda.", um centro de treinamento para aprendizagem de menores foi criado com os recursos do programa. Este começou a operar em 1981, de maneira semelhante às escolas do SENAI e estava formando de 20 a 25 aprendizes por ano. Com a recessão, a companhia não pode continuar a utilizar o programa. Tentativas de acertar um acordo de isenção com o SENAI e propostas para que o SENAI passasse a operar o centro como se fora uma das suas escolas falharam e o centro de treinamento foi encerrado em 1985. A companhia voltou, então, a utilizar os aprendizes do SENAI e, para outras qualificações, a estratégia seguida foi a de atrair mão-de-obra especializada de outras empresas.

Finalmente, na empresa que denominamos de "Treinamento Imediato S.A.", a responsável pelo departamento de treinamento parecia extremamente mal informada a respeito do treinamento operativo da empresa. Ela teve dificuldade em avaliar o impacto do programa de incentivos, mas declarou que, mesmo com a utilização do programa, permanecia na empresa um desinteresse dos gerentes em planejar as necessidades de treinamento de seus departamentos.

Os representantes da Associação Brasileira de Treinamento e Desenvolvimento (ABTD) têm consistentemente declarado na imprensa que os recursos públicos oferecidos pelo programa foram desperdiçados porque os empregadores compravam pacotes de treinamento que não eram apropriados às necessidades da empresa. Essa afirmação é curiosa já que o programa subsidia apenas um terço dos custos diretos de treinamento para as empresas. É de se perguntar, portanto, por que os empregadores estariam financiando treinamento que não resulta em aumento da produtividade da empresa.

Uma possível resposta está relacionada com o ponto acima sobre a estrutura de decisão da empresa. Em um dos estudos de caso - Treinamento de Supervisores S.A. - o chefe do departamento de treinamento declarou que, do estrito ponto de vista do seu departamento, o programa de incentivos trazia muitos problemas. Primeiro, porque os formulários do projeto a ser submetido ao CFMO

18.BARBOSA, M. et alii. Evidências sobre o Mercado Interno de Trabalho em um Processo de Crescimento Rápido. Projeto de Desenvolvimento de Recursos Humanos. UNDP-BRASIL BRA/70/550, 1976.

19.Em 1985, dois anos após o levantamento de campo, voltamos a oito das empresas pesquisadas. Uma descrição desses casos encontra-se em ROESCH, S. Op. cit. 
ocupavam muito tempo; segundo, porque o programa era, muitas vezes, utilizado para financiar treinamento ad hoc para indivíduos - que recorriam diretamente à diretoria ou gerência, e tratava-se de um treinamento que não beneficiava diretamente a empresa, só ocorrendo, em virtude, justamente da existência de recursos adicionais providos pelo governo.

Outra possibilidade é que os objetivos do treinamento não se limitam aos resultados esperados em termos de melhoria do desempenho no trabalho, mas que o treinamento estaria sendo usado como um prêmio, um fringe benefit para certas categorias de empregados, especialmente ao nível de gerência. Isso teria ocorrido através do financiamento de seminários, conferências e encontros em hotéis de luxo, ou seja, uma espécie de turismo disfarçado. Mesmo assim, permanece a questão: se os empregadores teriam feito essa escolha racionalmente ou se isso era resultado de estruturas de decisão erráticas dentro das empresas.

Quanto à idéia de que treinamento possa ser utilizado para envolver o trabalhador na companhia, observaram-se as seguintes variações. Num extremo caso de taylorismo (Centro de Treinamento Ltda.), observou-se que a companhia não tinha intenção de introduzir Círculos de Controle de Qualidade (CCQs), dado o receio de que as reuniões fossem ser utilizadas pelos sindicatos para a discussão de seus problemas comuns de salários e condições de trabalho. Essa idéia foi compartida pela "Companhia de Alto Treinamento", que é vista como um bom empregador pela comunidade local. Os responsáveis pelo treinamento argumentam que não há razão para envolver os trabalhadores coletivamente em questões de produção; a companhia prefere desenvolver dedicação individual ao trabalho e à questão da qualidade. Lealdade à companhia pode ser desenvolvida através de outros meios, como atividades sociais, argumentou o entrevistado no caso dessa última empresa.

Outro caso parece ilustrar um tipo de enfoque de "relações humanas" (Treinamento de Supervisores S.A.), onde a companhia estava preocupada em desenvolver treinamento comportamental ao nível de supervisão, com o propósito de desenvolver dentro da empresa "uma linguagem comum", "um modo especial de tratar os problemas" e "uma diminuição das rivalidades entre supervisores e subordinados". Finalmente, o caso da "Mercado Interno de Trabalho S.A." lembra o enfoque moderno de gerência onde a companhia está se voltando à automação e preocupada com problemas de qualidade do produto, face às exigências do mercado. Observa-se a preocupação em retreinar a mão-de-obra e introduzir CCQs para despertar nos trabalhadores a preocupação com a qualidade do produto e, também, atitudes de lealdade com a companhia.

\section{SUGESTÕES DE POLÍTICAS}

Sugestões para reformular o programa de incentivos ao treinamento têm sido apresentadas tanto pelas firmas que se beneficiam do programa, diretamente ao Conselho Federal de Mão-deObra, como por profissionais de treinamento através da imprensa. As sugestões dos empresários têm incluído propostas para aumentar o benefício, como por exemplo:

a) levantar o limite de dedução no imposto para $20 \%$, ao invés dos atuais $10 \%$;

b) desvincular o programa de alimentação do trabalhador do programa de treinamento, já que ambos competem no limite de $10 \%$ do imposto pago;

c) aumentar o prazo atual de três anos para a dedução de despesas de treinamento que excedem o limite de $10 \%$;

d) incluir no benefício o pagamento do salário dos aprendizes durante o periodo de treinamento prático na empresa; ou ainda

e) permitir o pagamento do salário dos menores envolvidos em aprendizagem em serviço e não apenas dos aprendizes do SENAI/SENAC ${ }^{\circ}$.

Até agora nenhuma dessas sugestões foi aceita pelo CFMO.

Outro grupo de sugestões envolve mudanças na operação do programa, com o propósito de torná-lo mais atrativo. Sugestões como a eliminação de formulários $e$, principalmente, a supressão do critério de aprovação prévia dos planos de treinamento das empresas pelo CFMO incluem-se nesse grupo. Em $1981^{21}$, a maioria dos formulários foi eliminada e outras medidas foram tomadas pelo Conselho com o intuito justamente de eliminar custos burocráticos do programa. Até a primeira metade de 1986, o critério de aprovação prévia ainda permanecia em vigor. Outras propostas envolvem a possibilidade de dedução das despesas de treinamento em outros impostos, como o IPI ou ICM, nos moldes do que já ocorre nas regiões norte e nordeste para as firmas isentas do pagamento do imposto de renda.

20.Simpósio: Situação e Perspectivas da Lei 6.297/75. São Paulo, 15 e 16 de Outubro de 1981.

21.BRASIL. Leis, decretos, etc. D.86.652. Decreto $\mathrm{n}^{\mathrm{Q}}$ 86.652 de 26 de novembro de 1981. In: Diário Oficial, Brasília. 
É claro que tanto a redução de custos burocráticos do programa como alterações na maneira em que este opera poderão ajudar a torná-lo mais atrativo para as empresas. Isso é aceitável na medida em que o propósito da política de treinamento seja meramente a redução dos custos de treinamento das firmas. Esses melhoramentos, no entanto, não irão eliminar o fato de o programa estar subsidiando treinamento que seria financiado pela empresa de qualquer maneira, como foi demonstrado neste trabalho e, provavelmente, não serão capazes de estender o benefício para as pequenas e médias empresas que não têm se beneficiado do programa na mesma proporção que as grandes empresas. Uma alternativa poderia ser para o governo injetar recursos no sistema SENAI/SENAC para o financiamento de programas especiais visando a atender as necessidades específicas dessas firmas.

Por outro lado, se o governo realmente deseja prover oportunidades de educação continuada para os trabalhadores, é preciso examinar a eficácia de políticas alternativas. Estas normalmente incluem:

a) provisão direta de treinamento tanto para trabalhadores empregados como desempregados;

b) a instituição de políticas mandatórias que envolvam as empresas através de taxação ou legislação; ou

c) a instituição de subsídios às empresas privadas.

Exemplos da primeira alternativa incluem tanto o Direct Training Services (DTS) como o Training Opportunities Scheme (TOPS) administrados pela Manpower Sercices Commission (MSC) no Reino Unido. No esquema DTS, o treinamento é recomendado e pago pelos empregadores e é desenvolvido tanto nas instalações da MSC como nas próprias empresas ou em outras instituiçōes. Nota-se semelhança com o modo de operar do SENAI no Brasil. O esquema TOPS se dirige a trabalhadores desempregados. Os cursos são desenvolvidos tanto nos centros de treinamento da MSC, como em outras instituições. Os cursos são grátis e os treinados recebem uma bolsa de estudos. No Brasil, poderíamos incluir o sistema SENAR -- Serviço Nacional de Aprendizagem Rural -.. nessa categoria.

A alternativa de políticas mandatórias implica em aumentar os custos de mão-de-obra para as empresas. É possível que outra taxa na folha de pagamento não seja viável, considerando-se que o total desses descontos já atinge $45 \%$ no Brasil. Uma possibilidade alternativa é a chamada licença-educação (paid cducational leave), a qual pode ser definida como "... tempo utilizado em atividades elucacionais organizadas durante o horario normal de trabalho, na qual uma parte ou o total do salário do treinado é mantida pelo empregador ou outra fonte" ${ }^{\prime 22}$. Essa alternativa tem sido implementada em diversos países europeus. A política tem que ser mandatória, porque os empregadores não se beneficiariam diretamente e o custo é alto, especialmente quando a duração da licença é longa e os custos indiretos decorrentes da ausência do trabalhador não são cobertos pelo trabalho de seus colegas. No Brasil, essa alternativa existe apenas em universidades e algumas empresas do governo e, normalmente, se restringe à educação de nivel superior.

Finalmente, há aquelas alternativas onde o governo cobre todos os custos de treinamento para as empresas. Esses esquemas são normalmente utilizados para combater desemprego. A experiência de subsídios ao treinamento nos EUA - onde um subsídio é dado à empresa para cada trabalhador que ela treina - é que, enquanto esses incentivos induzem as companhias mantenedoras a completarem o treinamento do trabalhador, eles não têm força para encorajar a companhia a reter o treinado depois de formado ${ }^{23}$. Outro exemplo é o de Youth Opportunity Programme (YOP), no Reino Unido, dirigido a jovens desempregados entre $16 \mathrm{e}$ 18 anos de idade, que recebem uma bolsa semanal paga pela MSC. Nesse caso, também, acredita-se que o esquema provê poucas oportunidades de treinamento no trabalho e que os jovens em treinamento são utilizados como uma fonte barata de trabalho ${ }^{24}$. No Brasil, os estágios arranjados pelo Centro de Integração Empresa e Escola (CIEE) sofrem da mesma acusação.

À guisa de conclusão, duas observações finais podem ser feitas. Primeiro, e como se pode deduzir da breve revisão acima, o sucesso da viabilidade das políticas envolvendo empregadores fundamentalmente depende do tipo de reação que eles apresentam, o qual é normalmente ligado ao objetivo de seus negócios. Nesse sentido, os resultados atingidos pelo programa de incentivos fiscais não são talvez específicos ao Brasil. É difícil

22.NOLLEN, S.D. "Paid educational leave: new element in firm-level manpower policy?". In: Industrial relations research association. New York, Annual Meeting, 30, Dec. 1977, pp.28-30, Proceedings.

23.GUNDERSON, M. "Impact of Government Training Subsidies". In: Industrial Relations, vol. 13, $\mathrm{n}^{\circ} 3$, oct., 1974, pp. 319-324.

24.JACKSON, M. \& HANBY, V. "Work Creation Programmes: Participant Responses". In: Industrial Relations, vol. $18, \mathrm{n}^{\mathrm{Q}} 2,1979$. 
argumentar que a reação dos empregadores seria diferente, se a mesma política fosse aplicada a qualquer outro país industrializado.

Segundo, embora aparentemente similar, as políticas de treinamento do Brasil diferem daquelas encontradas em outros países industrializados por uma série de razões. O tamanho dos programas e a sofisticação em sua operação e controle são as diferenças mais marcantes. Além disso, e independentemente da eficácia ou não dessas políticas, o fato é que em países industrializados há uma preocupação em atender as necessidades dos diversos grupos da população e são estabelecidas políticas específicas visando a esse propósito. Essa é talvez a maior diferença em relação ao Brasil; sua política de treinamento pode ser criticada por beneficiar um limitado número de trabalhadores, já que ela é quase que exclusivamente dirigida a $40 \%$ da população ativa que pertence ao setor formal do mercado de trabalho.

Tabela 1 - Despesas totais de treinamento, por ano e por empresa, 1976-1982. (Cr\$ milhares de 1982)

\begin{tabular}{|c|c|c|c|c|c|c|c|c|}
\hline Empresa & 1976 & 1977 & 1978 & 1979 & 1980 & 1981 & 1982 & Média \\
\hline $\begin{array}{r}23 \\
27 \\
31 \\
34 \\
44 \\
9 \\
12 \\
16 \\
17 \\
19 \\
22 \\
24 \\
25 \\
33 \\
38 \\
3 \\
13 \\
14 \\
15 \\
36 \\
40 \\
41 \\
43 \\
1 \\
2 \\
5 \\
21 \\
26 \\
30 \\
35 \\
7 \\
20 \\
29 \\
32 \\
42 \\
4 \\
8 \\
11 \\
28 \\
37 \\
39 \\
6 \\
18 \\
10\end{array}$ & $\begin{array}{r}3,871 \\
5,077 \\
53,970 \\
6,574 \\
17,400\end{array}$ & $\begin{array}{r}4,735 \\
40,605 \\
24,336 \\
21,048 \\
26,359 \\
3,278 \\
10,164 \\
2,092 \\
4,530 \\
6,009 \\
18,904 \\
2,424 \\
23,018 \\
6,779 \\
9,620\end{array}$ & $\begin{array}{r}12,346 \\
50,198 \\
36,353 \\
29,600 \\
19,362 \\
4,320 \\
12,667 \\
191 \\
4,085 \\
7,231 \\
8,694 \\
4,179 \\
50,071 \\
14,726 \\
13,788 \\
4,984 \\
5,123 \\
399 \\
6,932 \\
6,006 \\
1,465 \\
1,926 \\
42,799\end{array}$ & $\begin{array}{r}19,227 \\
49,112 \\
35,706 \\
23,243 \\
27,477 \\
3,673 \\
12,526 \\
637 \\
4,382 \\
306 \\
5,060 \\
4,140 \\
50,231 \\
22,879 \\
10,495 \\
2,328 \\
3,497 \\
143 \\
4,235 \\
8,493 \\
2,025 \\
7,643 \\
72,752 \\
7,242 \\
1,656 \\
1,093 \\
1,088 \\
17,282 \\
5,690 \\
11,148\end{array}$ & $\begin{array}{r}32,255 \\
27,350 \\
15,535 \\
17,309 \\
22,469 \\
3,326 \\
12,594 \\
640 \\
3,898 \\
3,686 \\
5,338 \\
3,459 \\
46,791 \\
17,666 \\
8,414 \\
1,072 \\
2,857 \\
1,558 \\
153 \\
5,887 \\
1,248 \\
6,157 \\
64,475 \\
6,609 \\
1,122 \\
1,566 \\
894 \\
10,880 \\
6,776 \\
23,334 \\
3,384 \\
1,562 \\
23,473 \\
156 \\
15,917\end{array}$ & $\begin{array}{r}19,788 \\
21,463 \\
25,262 \\
11,364 \\
8,931 \\
10,010 \\
3,70 \\
3,744 \\
7,158 \\
13,594 \\
1,565 \\
47,392 \\
21,592 \\
7,921 \\
1,152 \\
3,977 \\
1,613 \\
1,570 \\
7,796 \\
978 \\
2,764 \\
52,159 \\
1,749 \\
803 \\
8,354 \\
7,660 \\
50,283 \\
1,519 \\
4,506 \\
221 \\
17,099 \\
791 \\
7,050 \\
3,398 \\
784 \\
4,792 \\
35,000\end{array}$ & $\begin{array}{r}11,332 \\
10,635 \\
24,717 \\
\\
7,779 \\
9,683 \\
\ldots \\
\ldots, 275 \\
8,872 \\
3,629 \\
\\
21,171 \\
9,189 \\
846 \\
2,549 \\
1,144 \\
2,406 \\
8,168 \\
531 \\
1,786 \\
51,052 \\
869 \\
81, \\
1,152 \\
986 \\
3,670 \\
8,348 \\
75,314 \\
1,159 \\
5,086 \\
704 \\
11,094 \\
2,536 \\
8,607 \\
53,829 \\
980 \\
8,710 \\
28,398 \\
1,801 \\
3,599\end{array}$ & $\begin{array}{r}14,793 \\
29,206 \\
30,840 \\
18,190 \\
20,333 \\
4,475 \\
11,274 \\
890 \\
4,128 \\
5,444 \\
10,077 \\
3,233 \\
43,500 \\
17,469 \\
9,904 \\
2,076 \\
3,601 \\
971 \\
3,059 \\
7,270 \\
1,249 \\
3,285 \\
56,647 \\
6,926 \\
1,349 \\
1,270 \\
943 \\
9,047 \\
7,119 \\
40,020 \\
3,384 \\
1,413 \\
11,022 \\
360 \\
14,703 \\
1,664 \\
7,829 \\
28,614 \\
882 \\
6,751 \\
31,699 \\
1,801 \\
3,599\end{array}$ \\
\hline
\end{tabular}

Fonte: Amostra de empresas beneficiárias, Rio Grande do Sul, 1983. 
Tabela 2 - Taxas percentuais de mudança em despesas de treinamento para cada par de anos em que a empresa utilizou os incentivos fiscais, 1976-1982.

\begin{tabular}{|c|c|c|c|c|c|c|}
\hline Empresa & $1977 / 76$ & $1978 / 77$ & $1979 / 78$ & $1980 / 79$ & $1981 / 80$ & $1982 / 81$ \\
\hline 23 & 22 & 161 & 56 & 68 & -39 & -43 \\
\hline 27 & 700 & 24 & -2 & -44 & -22 & -50 \\
\hline 31 & -55 & 49 & -2 & -56 & 63 & -2 \\
\hline 34 & 41 & 41 & -21 & -26 & -34 & \\
\hline 44 & 51 & -27 & 42 & -18 & -60 & \\
\hline 09 & & 32 & -15 & -9 & $\ldots$ & $\ldots$ \\
\hline 12 & & 25 & -1 & -1 & -21 & -3 \\
\hline 16 & & -91 & 234 & 0 & $\ldots$ & $\ldots$ \\
\hline 17 & & -10 & 7 & -11 & -4 & $\ldots$ \\
\hline 19 & & 20 & -96 & 110 & 94 & 16 \\
\hline 22 & & -54 & -42 & 5 & 155 & -35 \\
\hline 24 & & 72 & -1 & -16 & -55 & 132 \\
\hline 25 & & 117 & 0 & -7 & 1 & $\ldots$ \\
\hline 33 & & 117 & 55 & -23 & 22 & -2 \\
\hline 38 & & 43 & -24 & -20 & -6 & 16 \\
\hline 03 & & & -53 & -54 & 7 & -27 \\
\hline 13 & & & -32 & -18 & 39 & -36 \\
\hline 14 & & & -64 & 990 & 4 & -29 \\
\hline 15 & & & -39 & -96 & 926 & 53 \\
\hline 36 & & & 41 & -31 & 32 & 5 \\
\hline 40 & & & 38 & -38 & -22 & -46 \\
\hline 41 & & & 297 & -19 & -55 & -35 \\
\hline 43 & & & 70 & -11 & -19 & -2 \\
\hline 01 & & & & -9 & $\ldots$ & \\
\hline 02 & & & & -32 & 56 & -50 \\
\hline 05 & & & & 43 & $\ldots$ & $\ldots$ \\
\hline 21 & & & & -18 & -11 & 23 \\
\hline 26 & & & & -37 & -60 & -16 \\
\hline 30 & & & & 20 & 13 & 9 \\
\hline 35 & & & & 109 & 115 & 50 \\
\hline 07 & & & & $\ldots$ & $\ldots$ & $\ldots$ \\
\hline 20 & & & & & 3 & -24 \\
\hline 29 & & & & & -81 & 13 \\
\hline 32 & & & & & 42 & 218 \\
\hline 42 & & & & & 7 & -35 \\
\hline 04 & & & & & & 221 \\
\hline 08 & & & & & & 22 \\
\hline 11 & & & & & & 1,484 \\
\hline 28 & & & & & & 25 \\
\hline 37 & & & & & & 82 \\
\hline 39 & & & & & & -19 \\
\hline 06 & & & & & & $\ldots$ \\
\hline 18 & & & & & & $\cdots$ \\
\hline 10 & & & & & & $\cdots$ \\
\hline
\end{tabular}

Fonte: Tabela 1. 
Tabela 3 - Média das taxas de mudança em despesas de treinamento das empresas beneficiárias

\begin{tabular}{|lcccrr|}
\hline $1977 / 76$ & $1978 / 77$ & $1979 / 78$ & $1980 / 79$ & $1981 / 80$ & $1982 / 81$ \\
\hline \multirow{1}{152}{} & 50 & 15 & -15 & -18 & -32 \\
& $\underline{27}$ & 12 & 3 & 23 & 21 \\
& & $\underline{32}$ & -90 & 114 & -15 \\
& & & $\underline{11}$ & 23 & 3 \\
& & & & -7 & 43 \\
& & & & $\underline{302}$ \\
\hline
\end{tabular}

Fonte: Tabela 2

Tabela 4 - Mediana das taxas de mudança em despesas de treinamento das empresas beneficlárias

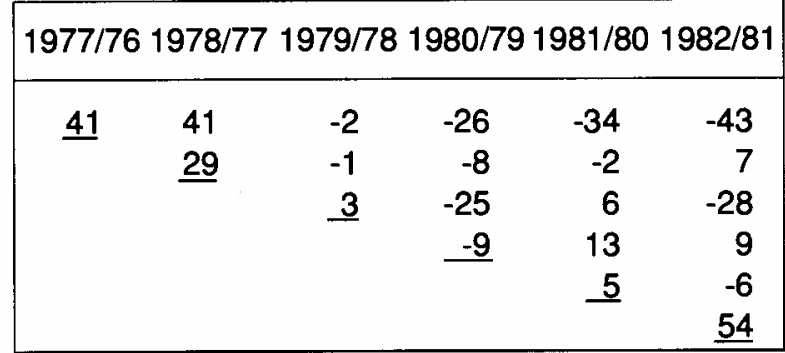

Fonte: Tabela 2
Tabela 5 - Média ponderada das taxas de mudança em despesas de treinamento das empresas beneficiárias

\begin{tabular}{|llllrr|}
\hline $1977 / 76$ & $1978 / 77$ & $1979 / 78$ & $1980 / 79$ & $1981 / 80$ & $1982 / 81$ \\
\hline \multirow{21}{*}{} & 26 & 5 & -26 & -25 & -30 \\
& $\underline{38}$ & -5 & -10 & 11 & -2 \\
& & $\underline{45}$ & -17 & -14 & -5 \\
& & & $\underline{13}$ & 44 & 38 \\
& & & & $\underline{-43}$ & -23 \\
& & & & &
\end{tabular}

Fonte: Tabela 2

Tabela 6 - Percentagem de empresas com aumentos em despesas de treinamento

\begin{tabular}{|c|c|c|c|c|c|c|}
\hline $1977 / 76$ & $1978 / 77$ & $1979 / 78$ & $1980 / 79$ & $1981 / 80$ & \multicolumn{2}{|c|}{$1982 / 81$} \\
\hline$+480 \%$ & $+480 \%$ & $+240 \%$ & $+120 \%$ & $+120 \%$ & & 0 \\
\hline$-1-$ & -1 & -3 & -4 & -4 & -3 & \\
\hline & $+7 \quad 70 \%$ & $+4 \quad 40 \%$ & $+4 \quad 40 \%$ & $+450 \%$ & +3 & $50 \%$ \\
\hline & -3 & -6 & -6 & -4 & -3 & \\
\hline & & $+450 \%$ & $+113 \%$ & $+563 \%$ & +2 & $25 \%$ \\
\hline & & -4 & -7 & -3 & -6 & \\
\hline & & & $+343 \%$ & $+360 \%$ & +3 & $60 \%$ \\
\hline & & & -4 & -2 & -2 & \\
\hline & & & & $+375 \%$ & +2 & $50 \%$ \\
\hline & & & & -1 & -2 & \\
\hline & & & & & +5 & $83 \%$ \\
\hline & & & & & -1 & \\
\hline
\end{tabular}

Fonte: Tabela 2 
Tabela 7 - Resumo das medidas de impacto

\begin{tabular}{|llllll|}
\hline Medida & $1978 / 77$ & $1979 / 78$ & $1980 / 79$ & $1981 / 80$ & $1982 / 81$ \\
\hline Média & negativo & positivo & parcialm. positivo & parcialm. positivo & positivo \\
Mediana & negativo & positivo & parcialm. positivo & parcialm. positivo & positivo \\
M.Ponderada & positivo & positivo & positivo & negativo & positivo \\
Percentagem & negativo & positivo & positivo & positivo & positivo \\
\hline
\end{tabular}

Fonte: Tabelas 3 a 6

Tabela 8 - História de treinamento e variação nas despesas de treinamento

\begin{tabular}{|c|c|c|c|c|c|c|}
\hline \multirow{6}{*}{$\begin{array}{l}\text { Variação na } \\
\text { Despesa de } \\
\text { Treinamento }\end{array}$} & \multicolumn{6}{|c|}{ História de Treinamento } \\
\hline & \multicolumn{3}{|c|}{$\begin{array}{l}\text { Empresas iniciando } \\
\text { Treinamento }\end{array}$} & \multicolumn{2}{|c|}{$\begin{array}{l}\text { Empresas estabelecidas } \\
\text { em Treinamento }\end{array}$} & \multirow{2}{*}{$\begin{array}{r}\text { Total } \\
16\end{array}$} \\
\hline & Aumentando & 7 & $54 \%$ & 9 & $32 \%$ & \\
\hline & Estável & 1 & $8 \%$ & 9 & $32 \%$ & 10 \\
\hline & Diminuindo & 5 & $38 \%$ & 10 & $36 \%$ & 15 \\
\hline & Total & 13 & $100 \%$ & 28 & $100 \%$ & 41 \\
\hline
\end{tabular}

Fonte: ROESCH, S. Op. cit., Cap. VIII, Tabela 61.

Tabela 9 - Utilização dos incentivos e variação nas despesas de treinamento

\begin{tabular}{|llrrrrr|}
\hline & & \multicolumn{2}{c}{ Utilização dos Incentivos } & \\
\cline { 2 - 7 } & & \multicolumn{2}{c}{ Tarde } & \multicolumn{2}{c|}{ Cedo } & Total \\
\cline { 2 - 7 } $\begin{array}{l}\text { Variação nas } \\
\text { Despesas de } \\
\text { Treinamento }\end{array}$ & Eumentando & 12 & $63 \%$ & 4 & $18 \%$ & 16 \\
\cline { 2 - 7 } & Estável & 1 & $5 \%$ & 9 & $41 \%$ & 10 \\
\cline { 2 - 7 } & Diminuindo & 6 & $32 \%$ & 9 & $41 \%$ & 15 \\
\cline { 2 - 7 } & Total & 19 & $100 \%$ & 22 & $100 \%$ & 41 \\
\hline
\end{tabular}

Fonte: ROESCH, S. Op. cit., Cap. VIII, Tabela 62, p.224.

\section{Tabela 10 - Sofisticação da política de treinamento e variação nas despesas de treinamento}

\begin{tabular}{|c|c|c|c|c|c|c|c|c|}
\hline \multirow{6}{*}{$\begin{array}{l}\text { Variação na } \\
\text { Despesa de } \\
\text { Treinamento }\end{array}$} & \multicolumn{8}{|c|}{ Sofisticação da Política de Treinamento } \\
\hline & \multirow[b]{2}{*}{ Aumentando } & \multicolumn{2}{|c|}{ Baixa } & \multicolumn{2}{|c|}{ Média } & \multicolumn{2}{|c|}{ Alta } & \multirow{2}{*}{$\begin{array}{r}\text { Total } \\
16\end{array}$} \\
\hline & & 1 & $17 \%$ & 4 & $33 \%$ & 11 & $50 \%$ & \\
\hline & Estável & 1 & $14 \%$ & 3 & $25 \%$ & 6 & $27 \%$ & 10 \\
\hline & Diminuindo & 5 & $71 \%$ & 5 & $42 \%$ & 5 & $23 \%$ & 15 \\
\hline & Total & 7 & $100 \%$ & 12 & $100 \%$ & 22 & $100 \%$ & 41 \\
\hline
\end{tabular}

Fonte: ROESCH, S. Op. cit., Cap. VIII, Tabela 63. 
Tabela 11 - Sofisticação da política de treinamento e história de treinamento

\begin{tabular}{|c|c|c|c|c|c|c|c|}
\hline \multirow{3}{*}{$\begin{array}{l}\text { História de } \\
\text { Treinamento } \\
\text { Empresas } \\
\text { Estabelecidas } \\
\text { em Treinamento }\end{array}$} & \multicolumn{7}{|c|}{ Sofisticação da Política de Treinamento } \\
\hline & \multicolumn{2}{|c|}{ Baixa } & \multicolumn{2}{|c|}{ Média } & \multicolumn{2}{|c|}{ Alta } & Total \\
\hline & 5 & $63 \%$ & 7 & $64 \%$ & 18 & $72 \%$ & 30 \\
\hline $\begin{array}{l}\text { Empresas Iniciando } \\
\text { Treinamento }\end{array}$ & 3 & $37 \%$ & 4 & $36 \%$ & 7 & $28 \%$ & 14 \\
\hline Total & 8 & $100 \%$ & 11 & $100 \%$ & 25 & $100 \%$ & 44 \\
\hline
\end{tabular}

Fonte: Roesch, S. Op. cit., Cap. VIII, Tabela 64.

Tabela 12 - Volume de treinamento, antes e durante a utilização dos incentivos fiscais

\begin{tabular}{|c|c|c|c|c|c|}
\hline \multirow{4}{*}{$\begin{array}{l}\text { Durante a } \\
\text { Utilização } \\
\text { dos incentivos } \\
\text { Fiscais }\end{array}$} & \multicolumn{5}{|c|}{ Antes da Utilização dos Incentivos Fiscais } \\
\hline & & & Ial & Abaixo & Total \\
\hline & Abaixo & & $5 \%$ & $1150 \%$ & 12 \\
\hline & Igual & 19 & $95 \%$ & $1150 \%$ & 30 \\
\hline & Total & & $100 \%$ & $22100 \%$ & 42 \\
\hline
\end{tabular}

Fonte: Roesch, S. Op. cit., Cap. VIII, Tabela 65.

Tabela 13 - Média ponderada das taxas de mudança em despesas de treinamento das empresas beneficiárias

\begin{tabular}{|c|c|c|c|c|c|c|c|c|c|c|c|}
\hline & & presas & $\mathrm{om} \mathrm{Im}$ & acto & & & & presas & $\mathrm{em} \operatorname{Imp}$ & icto & \\
\hline $77 / 76$ & $78 / 77$ & $79 / 78$ & $80 / 79$ & $81 / 80$ & $82 / 81$ & $77 / 76$ & $\cdot 78 / 77$ & $79 / 78$ & $80 / 79$ & $81 / 80$ & $82 / 81$ \\
\hline 45 & 18 & 14 & 3 & -44 & -43 & 10 & 33 & -2 & -49 & 9 & -24 \\
\hline & 83 & 1 & -7 & 1 & - & & $\underline{15}$ & 8 & 14 & 21 & -2 \\
\hline & & - & - & - & - & & & 45 & -17 & -14 & -5 \\
\hline & & & 64 & 88 & 42 & & & & $\underline{-26}$ & -37 & -16 \\
\hline & & & & - & $\underline{74}$ & & & & & $-\underline{43}$ & $\begin{array}{r}-23 \\
102 \\
\end{array}$ \\
\hline
\end{tabular}

Fonte: Tabela 2

Tabela 14 - O Impacto dos Incentivos (I) (Cr\$ milhares)

\begin{tabular}{|lrrrrr|}
\hline Cortes & 1976 & 1977 & 1979 & 1981 & Total \\
\hline (1) Número de Empresas & & & & & \\
Grupo com Impacto & 3 & 3 & 4 & 2 & 12 \\
Grupo sem Impacto & 2 & 7 & 3 & 4 & 16 \\
(2) Grupo com Impacto (metade dos & & & & & \\
valores observados) & 13.923 & 14.820 & 9.791 & 2.788 & 41.322 \\
(3) Grupo sem Impacto & 59.047 & 57.178 & 25.617 & 46.239 & 188.081 \\
(4) Total do Treinamento na Ausência dos Incentivos & 72.970 & 71.998 & 35.408 & 49.027 & 229.403 \\
(5) Impacto no Total do Treinamento $\left((2 / 4){ }^{*} 100\right)$ & $19.1 \%$ & $20.6 \%$ & $27.7 \%$ & $5.7 \%$ & $18 \%$ \\
\hline
\end{tabular}

Fonte: Tabela 1 
Tabela 15 - O Impacto dos Incentivos (II) (Cr\$ milhares)

\begin{tabular}{|lrrrrrrr|}
\hline Coortes & 1976 & 1977 & 1978 & 1979 & 1980 & 1981 & 1982 \\
\hline (1) Número de Empresas & & & & & & & \\
Grupo com Impacto & 3 & 3 & 0 & 4 & 0 & 2 & 2 \\
Grupo sem impacto & 2 & 7 & 8 & 3 & 4 & 4 & 0 \\
(2) Despesa Estimulada & & & & & & & \\
pelo Programa & 13.923 & 40.891 & 57.828 & 72.390 & 77.744 & 78.645 & 55.970 \\
(3) Total Deduzido do Imposto & 6.743 & 56.477 & 85.846 & 106.652 & 116.094 & 98.217 & 55.522 \\
(4) (2) $e(3)$ & 2.06 & 0.72 & 0.67 & 0.68 & 0.67 & 0.80 & 1.00 \\
\hline
\end{tabular}

Fonte: Roesch, S. Op. cit., Apêndice Estatístico, Tabelas 7.6 e 7.9

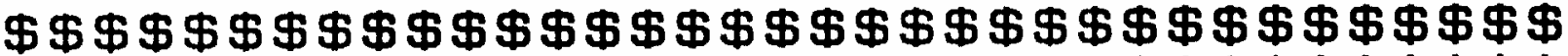

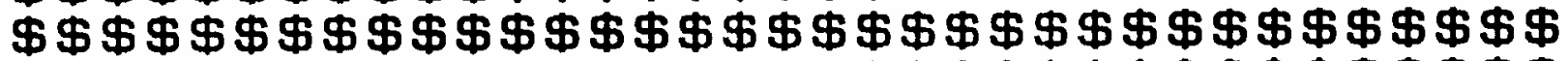

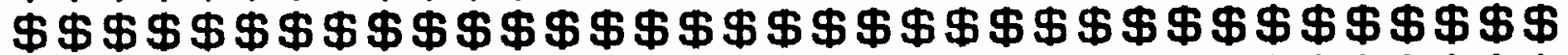

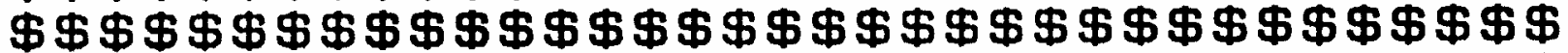

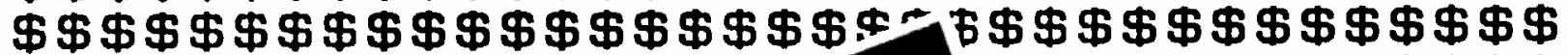

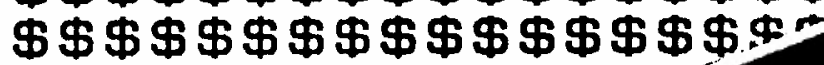

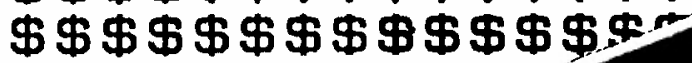

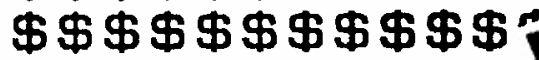

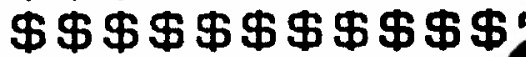

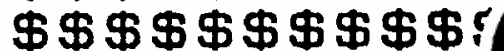

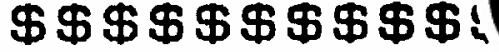

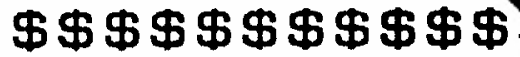

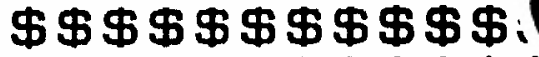

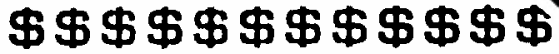

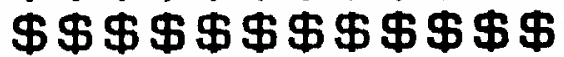

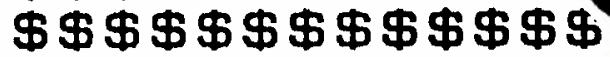

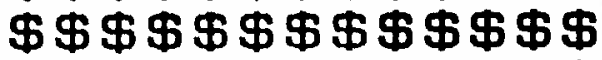

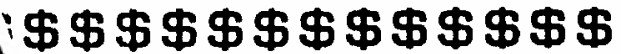

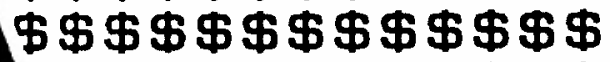

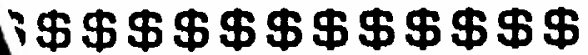

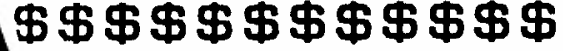

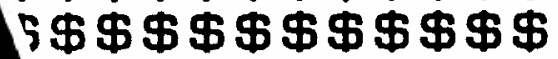

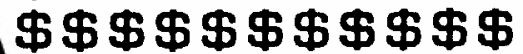

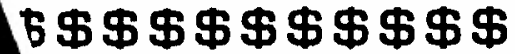

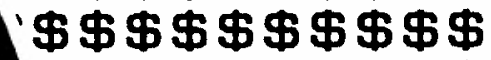

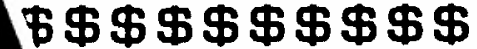
25

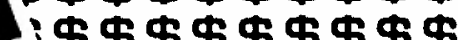

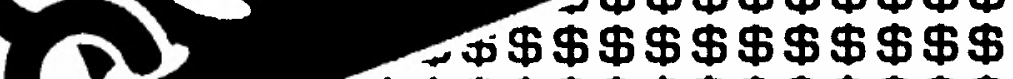

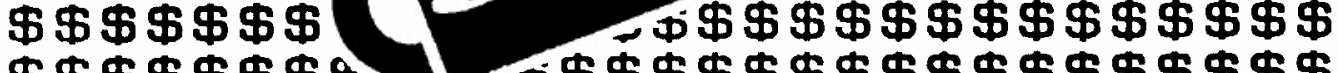

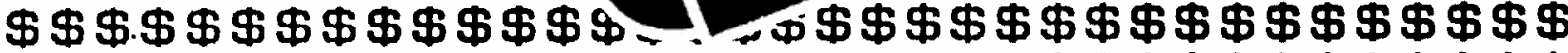

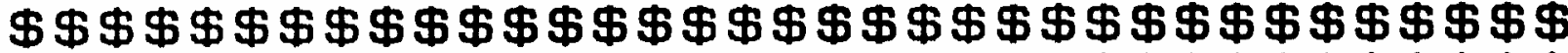

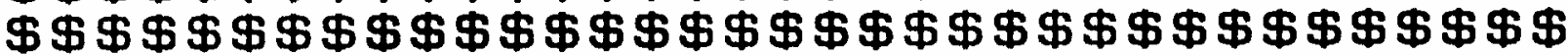

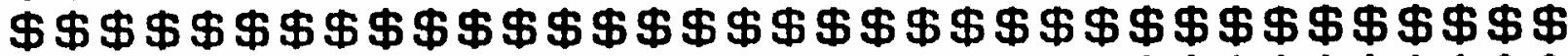

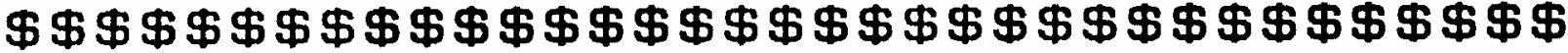

ABSTRACT: This article evaluates the programme of fiscal incentices for training introduced in Brazil in 1976. Moilels from economic and organization theory are reviewed and related to the provision of training by employers. Field work was conducted in 1983 in 44 beneficiary firms in a variety of industrial sectors in Southern Brazil. A follow up of eight cases was undertaken in 1985. The results suggest that the programme has increased the number of firms providing training. But has not increased the volume of training in firms which previously provided it. The total volume of training stimulated was nevertheless smaller than the government resources invested.

KEX TERMS: Training, fiscal incentives, human capital, policy evaluation, impact evaluation. 